\title{
E-Learning for Health-Care Workforce Development
}

\author{
L. Taylor', P.A. Abbott' ${ }^{2}$, K. Hudson' \\ 'Johns Hopkins School of Nursing \\ 2PAHO/WHO Collaborating Center for Nursing Knowledge, Information Management \& Sharing at the \\ Johns Hopkins University School of Nursing
}

\section{Introduction}

The impact of global workforce shortages are calling out for new and innovative ways to scale-up the health care workforce, particularly in the realm of nursing, primary care, and community health. Traditional types of education, constrained by "brick and mortar" models are increasingly being viewed as insufficient to handle the critical need for adequately educated frontline health care workers, especially in medically underserved areas. The use of information and communication technologies (ICT), while not a panacea to workforce crises, is proving to be a valuable adjunct to improving global health and its developing workforce.

The goal of this paper is to discuss the foundations of distributed e-learning in health and to survey some of the more innovative approaches to the use of elearning for workforce development.

\section{Background}

ICT is rapidly emerging as a powerful educational medium that offers innovative ways to disseminate information globally. Increasing numbers of the world's population are gaining access to knowledge resources as ICT use expands. As an example, the African region has been identified as the world's fastest growing mobile telephony market, with an annual growth rate of $62.4 \%$ [1]. China already has more cell phones than there are people in the US [2]. The African Medical Research and Education Foundation (AMREF) has instituted a program in Kenya that will "train-up" 22,000 nurses via distance education within 5 years [3]. Oregon Health \& Science University has initiated an online introductory program as part of the American Medical Informatics Association's (AMIA) $10 \times 10$ initiative to educate over 10,000 clinicians in medical informatics by the year 2010. After successful implementation for close to three years, course materials are now being translated into Spanish and are offered within areas of South America including Buenos Aires, addressing a Latin American audience [4].

Each of these citations illustrates fertile ground for innovative growth in a variety of global settings. The proliferation of ICT coupled with the need for rapid development and deployment of human resources in health makes the use of ICT a particularly appealing strategy for educational outreach and workforce development. While the use of ICT is not a panacea for global health woes, it may be a strategy to both scale up, and then, retain health 
workers. Many of the "push-pull" factors that encourage health workers to leave their workplaces involve isolation and lack of educational opportunity, two factors that ICT is particularly well suited to address.

The relationship of globalization and information accessibility is fundamentally changing the patient-provider relationship as well. More informed consumers are demanding more from the healthcare sector as new treatments and new modalities for communicating proliferate. The points are emphasized in the final report of the Committee on Health Informatics [5] which focused on the benefit of using ICT in health and healthcare, citing the power of the internet in providing patients, families, and health providers with easily accessible, rapidly expanding and unparalleled opportunities to learn, inform, and communicate.

Finally, the impact of opening access to information via ICT is markedly changing the fabric of societies. Areas once inaccessible and cut-off from new ideas and information are moving quickly into information empowered communities. In example, Mongolia, home to approximately 2.4 million people, is one of the most isolated regions in the world with more than two-thirds of the population living in rural and remote areas. As support from the USSR and successor states diminished in the 1990's, Mongolia was forced to move into a market economy, yet had almost no infrastructure, knowledge, or human resources to do so. The Canadian based International Development Research Centre (IDRC) initiated the Pan Asian Networking program (PAN), which in turn began funding efforts in Mongolia to increase the use of ICT. Today, Mongolia is a regional leader in Internet-based methods of development. "About 30,000 individuals - ranging from the prime minister to teachers and teenagers - are dedicated Internet users." [6]. One of the keys to Mongolia's success is training of informal community leaders - such as well-respected teachers and doctors to head the rural centers and promote the Internet. IDRC has continued its expansion into the ACACIA project in Africa, ICT in Bhutan to educate teachers, and in the Malay Archipelago in Indonesia where is partnered with the Universitas Terbuka (UT), the Open University of Indonesia [6]. The potential for outreach to impact workforce, from health to education and beyond, is increasing considerably.

\section{The Global Workforce Crises in Health}

The World Health Report [7] of 2006 concisely summarizes the issue of workforce. "At the heart of each and every health system, the workforce is central to advancing health. There is ample evidence that worker numbers and quality are positively associated with immunization coverage, outreach of primary care, and infant, child and maternal survival." [7, p. XV]

The sobering truth, however, is that in the globe's poorest regions (particularly sub-Saharan Africa) the workforce crises are crippling efforts to improve health. The 2006 WHR report reveals an estimated shortage of almost 4.3 million doctors, midwives, nurses and support workers worldwide. While the goals of increasing workforce seem straightforward and highly commendable, the mechanisms for achieving these goals are very complex. As is noted in the 2006 WHR, a "blueprint" approach to solving the issue is not feasible. Preparing sufficient numbers of skilled workers with the competencies to advance health for all requires the background, language and social at- tributes that will enable them to work within diverse settings and locales. Failing to adequately address contextual (e.g. cultural, socio-economic, political) realities can result in less than optimal results.

There are many known reasons for the workforce crises. The impact of HIV/AIDS has not spared healthcare workers. Workplace violence (genderbased and otherwise), particularly in conflict areas, is commonplace. Poor working conditions, poor pay, lack of educational opportunity, a growth in the aged and chronic disease patient populations, and isolation all contribute to low appeal as a career [7]. For those who are already workers in the healthcare industry, out-migration accelerates in the presence of the same conditions. The WHR of 2006 reveals that $50-90 \%$ of all global healthcare is provided by non-physician providers such as nurses, midwives and traditional birth attendants. Considering the global nursing shortage, it is hardly surprising that nurses and midwives are easily lured from developing nations; a trend projected to accelerate.

How can ICT be used as an adjunct to slow the outflow and scale-up human resources in healthcare? There are many avenues for growth in this sector. E-learning offers workers quality education and training within a convenient and just-in time virtual classroom that is designed and delivered to the learner's specific needs that results in an engaged citizenry and a skilled workforce for the digital economy [8]. Rapid growth in global telephony, an increase in internet accessibility, and the development of innovative ICT (such as the $\$ 150$ laptop) can all play important roles in fostering workforce scale-up and workforce retention. Further discussion of several of these progressive approaches follow. 


\section{Potential Solutions - Distributed E-Learning}

Distributed e-learning (DE) is not a new concept in healthcare education. Numerous examples of the use of "distance education" exist in the literature; however there are current examples which illustrate a shifting in traditional DE application. While it can be argued the DE is (and always has been) a method used to educate health workers, in many instances the use of DE was more one of convenience than necessity. In considering the global shift in this regard, one notices a growth in the use of ICT targeted specifically to workforce scale-up. Much of this has to do with the rapid proliferation of global connectivity, particularly in the growth of personal cell phone ownership and the growth of "information appliances" [9].

An example of the application of global connectivity for DE is the RAFT (Réseau en Afrique Francophone pour la Télémédecine) program. Through the coordination of a network for eHealth in Africa, Geneva University Hospitals have linked together to create a lowcost distance educational network throughout even the most remote rural areas of central Africa $[10,11]$. Challenged with an infrastructure and international bandwidth slower than a DSL connection, the RAFT program, which began in Mali, now extends to over 10 French-speaking African countries. RAFT successfully brings webcasting ( $25 \mathrm{kbits} / \mathrm{s})$ video conferences, tele-consultations and the ability of physicians and health providers to practice outside of the usually earmarked educational centers and universities within a capital city. This innovative program has managed to overcome barriers that normally inhibit the delivery of educational materials via electronic methods in low resource settings.
RAFT has opened new avenues for education of health care providers, increasing the potential for improvements in global health, particularly in Francophone West Africa.

Other examples of distributed elearning approaches include the Interprofessional Education Network (EIPEN) project. Through the use of podcasts, inter-professional e-learning tools, and international workshops, the EIPEN project is providing opportunities for health and social care students and practitioners to engage professionally to maximize teaching and learning. Six countries are participating in this effort; Greece, Finland, Sweden, Hungary, Poland, and the UK (http:// www.health.heacademy.ac.uk/projects/ eipen/). A similar example of outreach regarding the online education of health professionals is the MEDICOL (Medicine and Dentistry Integrated Curriculum Online) program. MEDICOL offers a delivery of streamed lectures, chat rooms and WebCT to medical and dental students across the Province of British Columbia in Canada (https:// ww w.med.ubc.ca/medicol2/ index.htm). Finally, thirty- two medical schools in France are connected via a meta-data search collaborative calledDocUMVF [12]. A subset of SCORM (Sharable Content Object Reference Model) metadata standards, the UMVF (http://www.umvf.prd.fr/) search tool allows medical students to access 3300 resources useful in their curriculum between the medical informatics laboratories of Rennes and Rouen. Efforts such as these are maximizing efficiency and improving outreach in the quest to meet the needs of a growing and increasingly complex healthcare domain.

Regulatory changes have given additional impetus to creative use of ICT for education in the health professions. In response to limited work hours al- lowed to junior residents under European laws, The Hospital at Night $(\mathrm{H} @ \mathrm{~N}) \quad$ program, (http://www. healthcareworkforce.nhs.uk/ hospitalatnight.html) provides supportive "virtual" coverage for doctors in training during the reduced coverage hours of the night. Launched in 2006, Intute: Health and Life Sciences ( http:/ /www.intute.ac.uk/) offers a wealth of resources compiled one database to guide academicians, students, and researchers from across the UK, HE and FE. Drawing from the Resource Discovery Network, (RDN) Intute makes available a variety of methods to guide users in efficient research by using RSS feeds to rapidly diseminate the most accurate information in areas including Medicine, Nursing, Midwifery, Bioresearch and Veterinary Medicine

The Pan-Asian Network (PAN) is an example of a very well established effort to increase access to ICT, particularly as related to healthcare workforce capacity building. PAN has several projects to deliver distance education and health services in Bhutan, Indonesia, Mongolia, the Philippines, and Viet Nam. The government of Mongolia, a participant in the PAN, has in its mission to deliver distance education to $75 \%$ of the population by 2010. When one considers the massive land mass that is served by the PAN coupled with pressing health issues and declining workforce in this region, it would seem as though the opportunities are considerable [6].

\section{Avenues of Future Growth for ICT Outreach for Workforce}

In light of the growth of the ICT market, including the massive escalation of cellular telephony, there has been increasing education to capitalize on this for health education. Such innovations 
as podcasting, WIKIs, blogs, short messaging service (SMS), using PDAs for targeted education deliveries, electronic Communities of Practice (eCoPs), and very low-bandwidth distance education are all growth areas. While the growth in this sector of the ICT market is escalating, there are only pockets of innovative applications found in healthcare education. Hopefully, uptake and innovation in this regard will increase.

The Agency for Healthcare Quality and Research (AHRQ) in the US has embarked on an interesting communication strategy with podcasting called "Healthcare 411". Podcasting is an artifact of the meteoric growth of the Ipod, and other similar portable audio devices where large amounts of recorded material can be stored on a single very small device. Three different types of podcasting have found their way into the educational domain. Audio podcasting in MP3 files is the most common and is used frequently by educators. Enhanced podcasting enables the insertion of chapter markers, which allow for easier indexing. The third type is audio/video podcasting using MP4 files. The use of podcasting allows for delivery of educational materials that can be used by the learner at their own pace and place. In developing nations where the oral tradition is deeply engrained in the culture, audio podcasting may be a particularly effective way to educate. AHRQ has begun to capitalize on this growth and has many podcasts on a variety of health topics available for free download (http://www.healthcare411.org/).

The use of SMS or short message service is also gaining popularity for a variety of educational uses. While not as robust as podcasts or other forms of ICT supported DE, there are still interesting avenues for use. In example, the delivery of targeted health mes- sages to previously inaccessible patients in rural settings is being used to increase adherence with TB treatment protocols in South Africa [13]. Elder and Clarke also cite the potential for use of SMS for informing public health officials of syndrome outbreaks and delivering specific health messages to providers and patients. Considering the massive growth of global telephony particularly in areas where internet access is limited, how could we "reach and teach" scores of cell phone connected persons?

The emergence of virtual or electronic CoPs is an additional avenue of ICT supported learning which may prove to be a strategy for workforce development. An example of one such e$\mathrm{CoP}$ is the Global Alliance for Nursing $\&$ Midwifery, a project initiated out of the WHO Department of Human Resources for Health, the Office for Nursing \& Midwifery, and the Johns Hopkins University School of Nursing Collaborating Center (http:// my.ibpinitiative.org/public). This platform designed for nurses and midwives serves as an open knowledge exchange e-CoP with a current membership of 1,300 from approximately 120 different countries. This platform supports open discussion, contains an open source library of materials and tools, and is used for continuing education delivery (live and then archived for continual use). Hara and Hew [14] have also discussed the use of an e-CoP for knowledge exchange and education. Using a electronic CoP not only opens avenues for dispersed clinicians to access resources and continuing education, it may also reduce the sense of isolation that contributes to out-migration.

Finally, the Digital Dividend Project Clearinghouse is an example of a global effort designed to distribute information to locations and sectors around the world that are without advanced technologies and web access using a variety of the afore-mentioned technologies. The Clearinghouse is creatively aligning ICT services to available resources, depending on world wide variation in search requirements (www.digitaldividend.org). Examples of resources from the Clearinghouse include programs that allow access to digital resources from very low bandwidth settings. GetWeb is described in the Clearinghouse as a Web-to-mail service designed to make the WWW accessible for human rights organizations and educators who have limited internet connections. Google by Email is cited as a resource that returns internet search results via emails and the Time Equals Knowledge (TEK) project has built a low connectivity search engine that offers internet capabilities for telephone users (http:// www.digitaldividend.org/marketplace/ marketplace_07.htm). Finally, Bellanet is mentioned by the Clearinghouse as an international non-profit initiative with a mission to promote and facilitate effective collaboration, especially through the use of information and communication technologies (ICTs) from its four offices in Ottawa, San José (Costa Rica), Kathmandu and Kampala (http://home.bellanet.org/index.php).

Each of these initiatives is evidence of the growth of innovative ICT in the global market. Many such approaches are being used by NGO's, Ministries of Health, private foundations, educational institutions to "reach and teach", particularly in relation to healthcare improvement, poverty reduction, and the education and retention of the healthcare workforce. There is room for continued creativity and growth, as the availability of connectivity increases, technological innovations expand, and the status of global health continues to challenge us to think and do in new ways. 


\section{Summation and Conclusion}

E-learning enables us to outreach and offer training that is current, readily accessible, and highly accommodating to a variety of learning styles, paces, and places $[15,16]$. The ability to deliver education and knowledge to the place of need rather than uprooting individuals to attend educational sessions outside of their communities is an important tool in scaling up and retaining workforce. Technological support for individual learning styles within risk free environments has the potential to prepare a stronger, highly motivated, and interconnected workforce. Within economically-strapped countries and regions, a more intuitive and well prepared workforce attracts additional resources and investments from outside companies, such as the case in India whose information economy is growing dramatically, benefiting entire regions.

Global healthcare is an intercontinental challenge requiring multi-pronged strategies in order to improve. One of these strategies involves solving the complex issues of workforce scale up and retention. Without an adequate workforce to deliver the care required to reduce disease, efforts to reduce human suffering will not advance. It is our belief that ICT-based e-learning will enable us to make significant progress in workforce scale up and retention.

\section{References}

1. International Telecommunications Union (nd). Retrieved January 7, 2008 at: http://www.itu.int/ net/home/index.aspx

2. Friedman, T. The World is Flat: a Brief History of the Twenty-First Century. Farrar, Straus and Giroux: NY; 2005.

3. International Finance Corporation/World Bank (n.d). The Business of Health in Africa: Partnering with the Private Sector to Improve Peoples Lives. US Department of Health and Education. Available online at: http://www.ifc.org/ifcext/ healthinafrica.nsf/AttachmentsByTitle/ IFC_HealthinAfrica_Final/\$FILE/ IFC_HealthinAfrica_Final.pdf

4. Hersh, W. \& Williamson, J. Educating 10,000 informaticians by 2010 : the AMIA $10 \times 10$ program. Int J Med Inform 2007;76(5-6),377-82.

5. Final Report of the Committee on Health Informatics. Johns Hopkins University, Bloomberg School of Public Health, School of Medicine, School of Nursing. August, 2007.

6. Connecting People-Changing Lives, 2005. Available at: http://www.idrc.ca/IMAGES/ICT4D/PanAsia/ PAN/intro.html\#2

7. World Health Report, 2006. The World Health Report 2006: Working Together for Health. World Health Organization, Geneva. Accessible online at: http://www.who.int/whr/2006/en/

8. Pantazis, C. Executive Summary: A vision of Elearning for america's workforce; $2001 \mathrm{http} / /$ www.learningcircuits.org/2001/aug2001/ pantazis.html; retrieved January, 11, 2008).

9. Abbott, P. (in review). Clinical Usability of a Handheld Information Appliance: The Impact of Form Factor on Workflow, Efficiency, and Safety. JAMIA.

10. Bagayoko C, Geissbuhler A. Telemedicine in Western Africa (RAFT); 2006 Available online at: https:/ /www2.unil.ch/sol2006/slides/thursday/ bagayoko_sol2006.pdf

11. Geissbuhler A, Bagayoko C, Ly O. The RAFT network: 5 Years of distance continuing medical education and tele-consultations over the Internet in French speaking Africa. Int J Med Inform 2007;76 (5-6),351-6.

12. LeBeux P, Fieschi M. Virtual biomedical universities and e-learning. Int J Med Inform 2007;76 (56),331-5.

13. Elder L, Clarke M. Past, present and future: experiences and lessons from telehealth projects Open Medicine 2007;1(3):e166-70.

14. Hara N, Hew KH. A Case Study of a Longstanding Online Community of Practice Involving Critical Care and Advanced Practice Nurses. Proceedings of the 39th Hawaii International Conference on System Sciences; 2006. Available online at: http:// ieeexplore.ieee.org/ie15/10548/33367/01579587.pdf

15. Brown JS, Adler RP. Minds on fire: Open education, the long tail, and learning 2.0. Educause 2008; 43(1), 16-32.

16. Browne L, Mehra S, Rattan R, Thomas G. Comparing lecture and e-learning as pedagogies for new and experienced professionals in dentistry. British Dental Journal 2004;197(2),95-7.

\section{Correspondence to:}

Dr. Laura A. Taylor

The Johns Hopkins University School of Nursing

525 N. Wolfe Street, Room 457

Baltimore, MD 21205-2110

Tel: +1 4105029342

E-mail: Itayl034@son.jhmi.edu 